\title{
Applications of active IRT to the cultural heritage study
}

\author{
S. Paoloni`, U. Zammit, N. Orazi, F. Mercuri, M. Marinelli, F. Scudieri, Dipartimento di Ingegneria Meccanica, Università
} Tor Vergata, Roma.

*Corresponding author: stefano.paoloni@uniroma2.it

\section{Introduction}

Active infrared thermography (IRT) is a non-destructive technique for the study of the cultural heritage [1]. More specifically, by monitoring the heat diffusion process within the sample, it provides information on the material and on the structure of the artifacts. In this work, an overview of IRT application to different artistic and historical artifacts is presented and discussed. In particular, different books have been studied, enabling the detection of structural features, defects and texts hidden beneath the surface of several volumes. Moreover, many kinds of archeological findings and materials have also been analyzed by IRT. Finally, some thermographic investigations have been carried out on a bronze sculpture obtained by lost wax casting, which allowed the detection and the analysis of several workings normally carried out on the bronze after the casting. They include repairs of the sculpture, the filling of holes and the cold working of the surface, all of which appearing concealed beneath the polished and patinated surface of the sculpture [2].

\section{Experimental}

Several kind of art and historic artifacts like books and documents, archaeological findings, and artworks have been investigated by active IRT which allows to reveal structural features and inhomogeneities in the materials It provides information on the surface and subsurface structure of the artifacts by analyzing the heat diffusion process induced within the sample by appropriate thermal stimulations and usually produced by the absorption of the light emitted by different sources (lamps, lasers, etc.). More specifically, we report on results obtained by the application of active IRT to the study of a bronze sculpture made by lost wax casting, where the workings performed after the casting on the bronze surface, (repairs, fillings, surface cold working, etc,) are generally concealed under the final polishing and patination [4], and also of different archaeological findings, such as the study of the

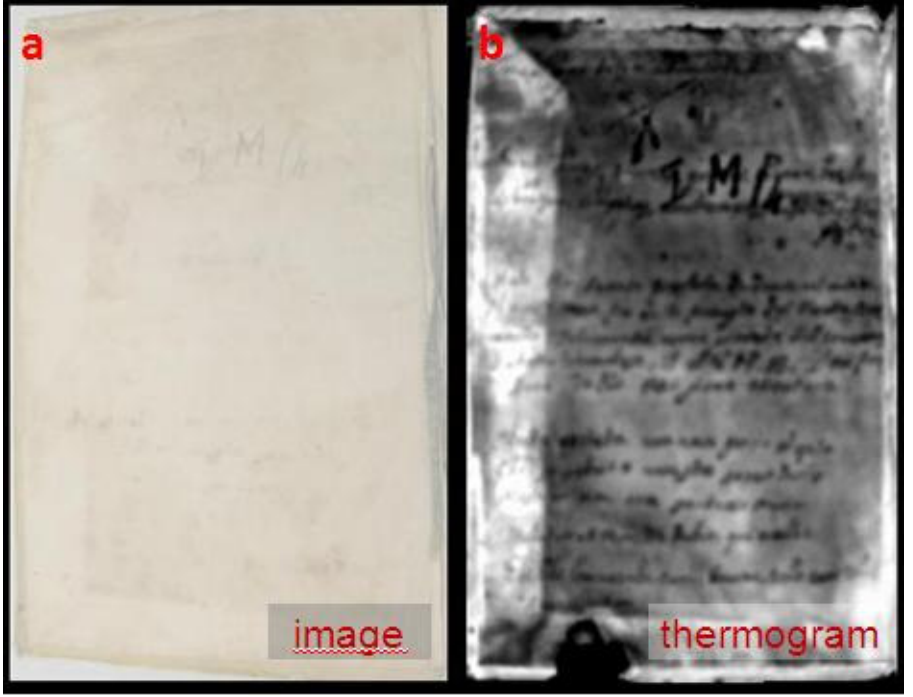

Fig. 1 - Photograph (a) of a seventeenth century volume. The thermogram (b) shows the writing of a leaf beneath the end paper concretions in a Roman terracotta [1]. Active IRT has been also finally used to study historical bookbindings [3] and texts hidden under the endleaf of ancient book, such as the writing of an earlier manuscript leaf used for the binding beneath that of the end paper shown in Fig. 1. 
The application of active IRT to the investigation of the cultural heritage also stimulated its integration with methods such as the other non-destructive digital imaging techniques. In this regard, a new system for 3D-termography based on the integration of 3D laser scanning and active IRT, has been developed and successfully tested on some of the studied cultural heritage artifacts. The results of the thermographic analysis have been integrated with the ones obtained from 3D scanning technique to create a 3D thermographic reconstruction, such as the one of the seventeenth century volume in Fig. 2, where the surface and sub-surface features appear in their position on a 3D geometrical model of the artifact (patent pending).

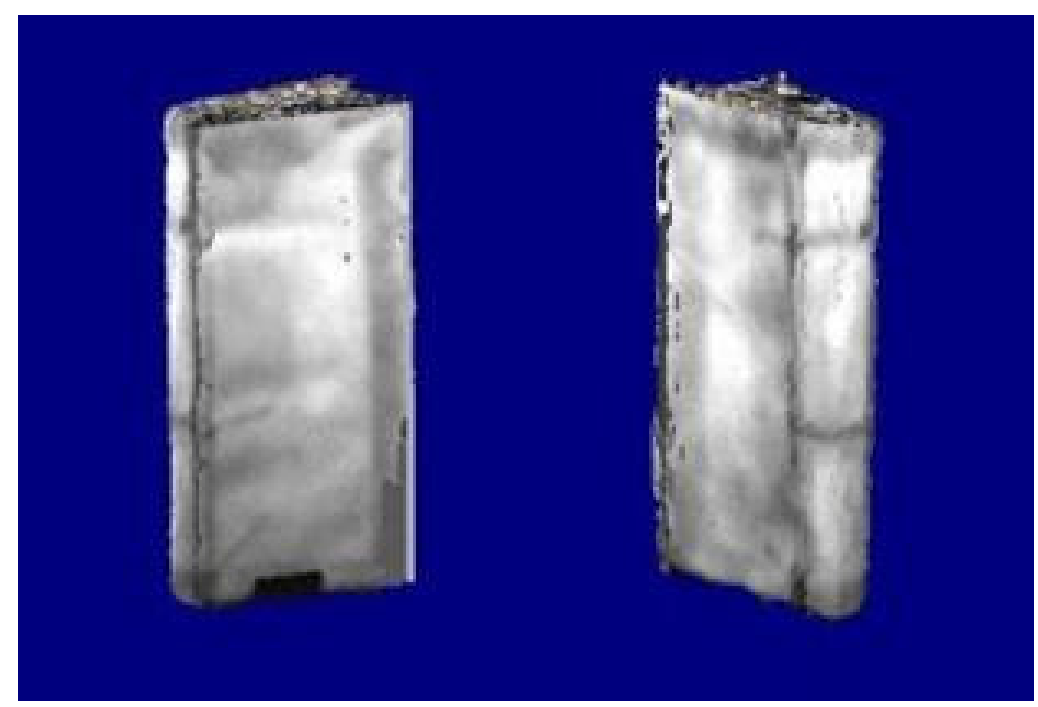

Fig. 2 - 3D thermographic recostruction of a seventeenth century volume.

\section{References}

[1] F. Mercuri, U. Zammit, N. Orazi, S. Paoloni, M. Marinelli, F. Scudieri, "Active infrared thermography applied to the investigation of art and historic artefacts" Journal of Thermal Analysis and Calorimetry, 104, 2, 475-485 (2011).

[2] Orazi N., Mercuri F., Paoloni S., Zammit U., Marinelli M., Scudieri F., Salerno C.S., Giuffredi A., Thermographic inspection of historical bronze statues, Proceedings of art'11, Florence april $13^{\text {th }}-15^{\text {th }}$.

[3] M. Marinelli, F. Mercuri, F. Scudieri, U. Zammit, G. Colombo, Thermographic study of microstructural defects in deteriorated parchment sheets, J. Phys. IV, 2005, 125, 527-529. 